\begin{tabular}{|c|c|}
\hline Citation & $\begin{array}{l}\text { Bram Vervliet, Dirk Hermans (2013), } \\
\text { Translation: That's the question, } \\
\text { Biological Psychology, 92(1),1. }\end{array}$ \\
\hline Archived version & $\begin{array}{l}\text { Author manuscript: the content is identical to the content of the published } \\
\text { paper, but without the final typesetting by the publisher }\end{array}$ \\
\hline Published version & http://dx.doi.org/10.1016/..biopsycho.2012.11.002 \\
\hline Journal homepage & http://www.journals.elsevier.com/biological-psychology/ \\
\hline Author contact & bram.vervliet@ppw.kuleuven.be \\
\hline & + $32(0) 16326117$ \\
\hline IR & https://lirias.kuleuven.be/handle/123456789/379174 \\
\hline
\end{tabular}

(article begins on next page) 



\title{
Translation: That's the question
}

\author{
Bram Vervliet, Dirk Hermans ${ }^{a}$
}

${ }^{a}$ K.U. Leuven, Faculty of Psychology and Educational Sciences, Tiensestraat 102, 3000 Leuven, Belgium 
Human fear conditioning represents one of the earliest applications of Pavlovian conditioning in humans. In 1937, Hovland published a series of studies on human fear conditioning (although he did not use this term) and established most of the fundamental Pavlovian principles, such as extinction, generalization, return of fear, partial reinforcement effects (Hovland, 1937a, 1937b, 1937c). Since these seminal papers, human fear conditioning research has always been around, but only slowly accumulating. A web of science $®$ search on 'human fear conditioning' (retrieved on May 14, 2012) shows that until 1990, only a few papers were published each year. Since 1990, however, the number of published papers has increased exponentially, hitting 170 in 2011. This vast increase in human fear conditioning research is unprecedented and establishes human fear conditioning as a research field in its own right. The current special issue in Biological Psychology is a snapshot of the exciting state that this research field is in. The topics that are covered by the different contributions provide a good overview of most current major topics of research in this field.

The diversity of these topics is remarkable, and mirrors the wide range of research disciplines that have embraced the human fear conditioning procedure. One of the major advantages of the human fear conditioning procedure is that it is an outstanding translational research tool. Results from animal fear conditioning research can be validated in human samples, using closely similar procedures and even measures (e.g., the fear-potentiated startle reflex). This has advanced our knowledge of the brain processes underlying human fear learning, our understanding of the memory processes involved in the maintenance of fear and of the possibility to erase fear memories, and insights in behavioral processes such as extinction, return of fear and avoidance. On the other hand, human fear conditioning also provides a translational tool between fundamental and clinical research on anxiety. Here, the influence of individual differences on the development of anxiety can be examined in an objective way. Also, new treatment techniques can be screened under experimentally controlled conditions. Because human fear conditioning provides concurrent translations between animal based research and human research and between experimental basic research and applied clinical research, it has become an important bridge between these two major research areas.

In our view, it is the legacy of Pavlov's groundbreaking work that has made this interdisciplinary and translational research possible. It is the simplicity of the fear conditioning procedure (neutral stimulus followed by aversive stimulus) that allows researchers from different backgrounds to transfer knowledge and combine their results. The procedure is truly translational: it allows researchers to use common terms and to speak the same 'language'. Any research discipline that wants to move forward needs an agreement on the fundamental experimental procedure that combines as many different interests as possible. Hovland's pioneering work has laid the foundations for an exciting discipline that is accumulating knowledge at a fast pace. It is our hope that this special issue may contribute to consolidate and expand this exciting development. 


\section{REFERENCES}

Hovland, C. I. (1937a). The generalization of conditioned responses: I. The sensory generalization of conditioned responses with varying frequencies of tone. Journal of General Psychology, 17, 125 148.

Hovland, C. I. (1937b). The generalization of conditioned responses: III. Extinction, spontaneous recovery, and disinhibition of conditioned and generalized responses. Journal of Experimental Psychology, 21, $74-62$.

Hovland, C.I. (1937c). The generalization of conditioned responses. IV. The effects of varying amounts of reinforcement upon the degree of generalization of conditioned responses. Journal of Experimental Psychology, 21, 261-276. 
Dienst Onderzoekscoördinatie Huis Bethlehem Schapenstraat 34

B-3000 Leuven

Tel.: +3216324065

Fax: +3216324198

onderzoek@kuleuven.be

www.kuleuven.be 